\title{
Women live longer than men
}

\author{
Ginter $E^{1}$, Simko $V^{2}$ \\ Institute of Preventive and Clinical Medicine, Bratislava, Slovakia. ginter.emil@mail.t-com.sk \\ University of New York, Downstate Medical Center at Brooklyn, USA. simko2@verizon.net
}

\begin{abstract}
In most parts of the world women live longer. This gender gap in life expectancy (LE) is remarkable and it has challenged scientific research for decades. Closer analysis of geographic differences related to such gender gap and attempts to recognize its cause may provide a powerful tool to understand the basic process of aging and to device preventive health care strategies. In countries with established socio-economic order women live on the average 4-7 years longer. The main contributing factor is higher cardiovascular disease (CVD) morbidity and mortality in men. In the European established democracies male mortality is on decline and the gender gap in LE is becoming smaller. Current trends in Iceland and in other Scandinavian countries indicate that by the year $\mathbf{2 0 5 0}$ men will live as long as women. Unfortunately, the gender gap continues to grow in the countries of the former Soviet influence where it represents up to 13 years. Dependence of the gender gap on the socio-economic order of a particular society points out the importance of environmental factors. Other mechanisms influencing the gender difference are the different hormonal and genetic function (Fig. 6, Ref. 23). Full Text in PDF www.elis.sk.

Key words: men, women, life expectancy, environment, hormonal and genetic function.
\end{abstract}

Life expectancy at birth (LE) represents an average number of years that a newborn is expected to live if current mortality rates continue to apply. LE reflects the overall mortality level of a population. It summarizes the mortality pattern that prevails across all age groups - children and adolescents, adults and the elderly.

There has always been a gap in the LE of males and females, and it has typically grown over time. From 1900 to the late 1970s this gender gap increased in favor of women from 2 to 8 years. Remarkably, in recent decades in countries with well functioning economy this gap decreased $(1,2)$. For the year 2009 the world mean LE was 64.52 years for males and 68.76 years for females. Gender difference in LE ranges from four to six years in North America. In Europe it is from 3 (Iceland) to more than 13 years (Russia).

The reasons for the difference between male and female LE are not fully understood. Certainly, hormonal and genetic factors have a prominent and complex role. Environmental and socioeconomic influences also weigh in. Men are more frequently exposed to occupational hazards, they drive more miles, drink more alcohol and smoke more, they are even more often exposed to trauma, including homicide. An analysis of gender difference affecting longevity may help to understand the basic process of aging and establish strategies to improve general health and provide more meaningful lives. The gap in LE between males and females appears to represent a sensitive indicator of the overall functioning of a particular society.

${ }^{1}$ Institute of Preventive and Clinical Medicine, Bratislava, Slovakia (emeritus), and ${ }^{2}$ State University of New York, Downstate Medical Center at Brooklyn, USA

Address for correspondence: E. Ginter, RND, DSc, Racianska 17, SK83102 Bratislava, Slovakia.
Present trend in gender life expectancy in Europe and in the world.

Figure 1 illustrates the difference in male and female LE in Europe (data mostly from 2007-2008). At the first glance it is obvious that the most extensive gender gap in Europe is in the countries of the former Soviet Union. Maximum difference is in Russian federation: women live on the average 13 years longer. Several other countries of former USSR demonstrate a gender gap of more than ten years. Next in the extent of gender gap, about seven years, are former Soviet satellites in eastern and central Europe. In established European democracies the gender gap is less

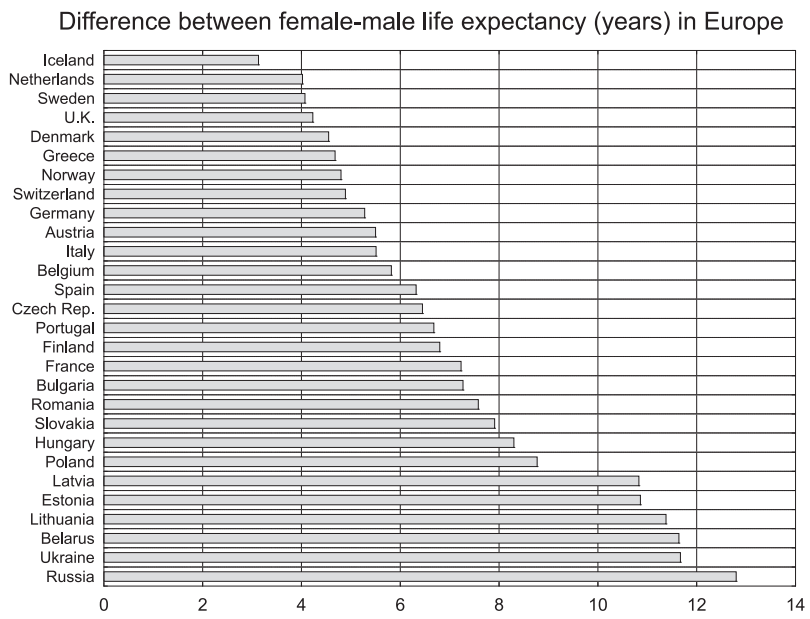

Fig. 1. Difference between male-female LE in Europe. According to WHO (2) mostly from years 2007-2008. 


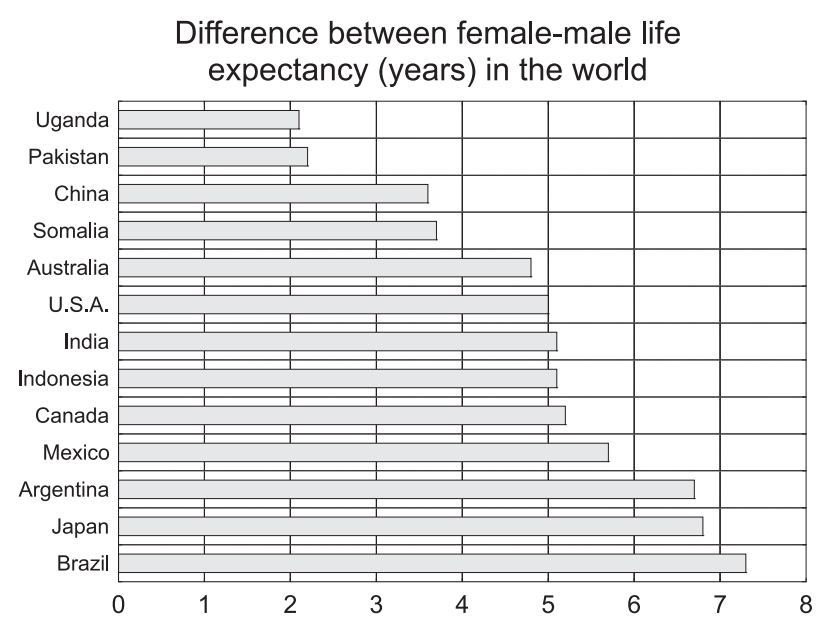

Fig. 2. Difference between male-female LE in the world. According to CIA (3) mostly from year 2009.

then six years. In countries with very efficient social and health care, the gender gap is close to four years and in Iceland only three years. The gender gap in LE in France, Portugal, Finland and Spain is related mainly to good LE in women.

Figure 2 summarizes the different LE between men and women in the non-European world. The values vary considerably, indicating less cohesive and more complex socio-biological environment compared to Europe.

The gender gap in Australia, Canada and in the USA is about five years. Argentina, Brazil and Japan have the gap in LE about seven years. The value of the gap is multifactorial. Japanese women live substantially longer while Brazilian men have markedly shorter LE.

Of all countries surveyed, men live longer than women only in the South African continent. Poor life expectancy of women in South Africa, Lesotho, Namibia, Zimbabwe, Malawi and Mozambique is possibly related to the more devastating effect of HIV infection in women.

Biologic factors contributing to different life expectancy in men and women

The basal metabolic rate is about 6 percent higher in adolescent males than females and increases to by about 10 percent after puberty. Females tend to convert more food into white adipose tissue, while men convert more ingested calories into muscle and circulating lipids including LDL-cholesterol. Women have substantially higher (the ,good“) HDL cholesterol. In our previously unpublished study of individuals in eight Slovak regions, we examined the effect of gender on the atherogenic index LDL/HDL. Figure 3 documents a marked sex difference in this index in all age groups: it confirmed a higher risk of atherogenesis in males.

\section{Cardiovascular mortality}

Figure 3 suggests an essential cause of shorter LE in males: cardiovascular disease (CVD) morbidity and mortality at age 0-64

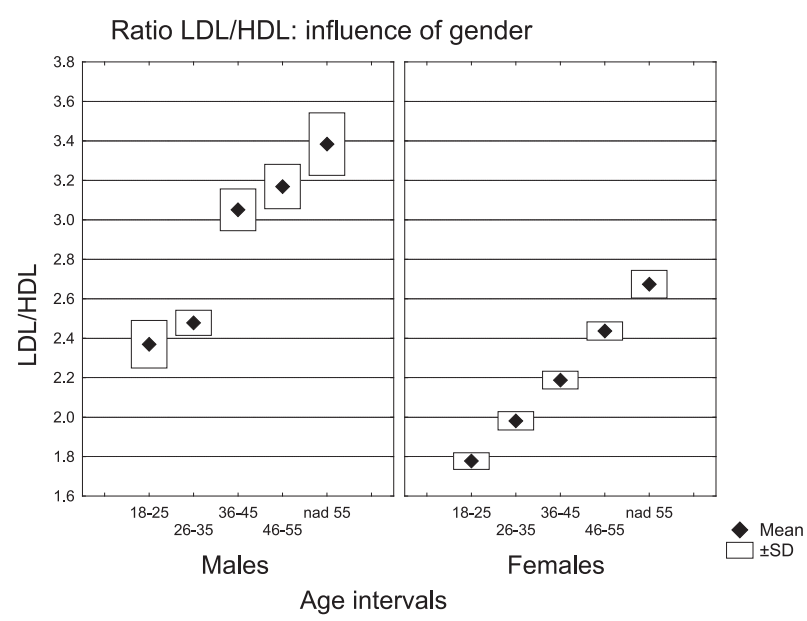

Fig. 3. Influence of gender and age on low density/high density lipoproteins (LDL/HDL) in Slovakia (not published).

\section{Premature cardiovascular mortality in Sweden}

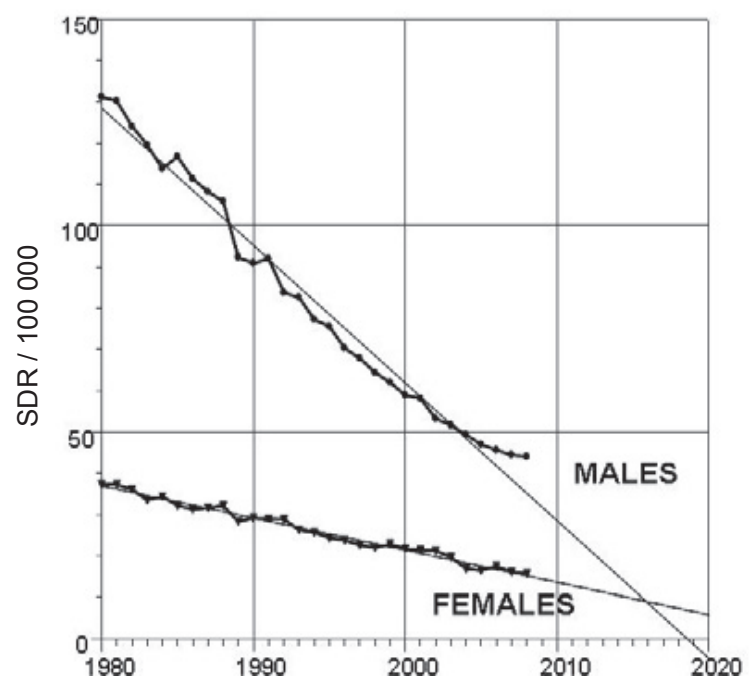

Fig. 4. Decline of male and female premature cardiovascular mortality in Sweden. According to WHO (2).

(2). In Europe, males in 1980 experienced almost double the CVD mortality reported in females. In the following years this gender difference steadily declined, mostly because male CVD mortality prominently decreased $(p<0.001)$. This marked decrease in gender difference of CVD mortality is depicted in Figure 4. In countries with well developed health care like Sweden, CVD mortality in men and women in 2020 will probably be the same.

The gender gap in LE in the developed European countries (Sweden, Switzerland, Netherlands) is presently four years and it exhibits a strong trend to decline, In the Czech Republic there is a steady although only moderate reduction in the gender gap in LE (Fig. 5). In the countries of the former Soviet Union this gender gap continues to grow. 
Female-male difference in life expectancy

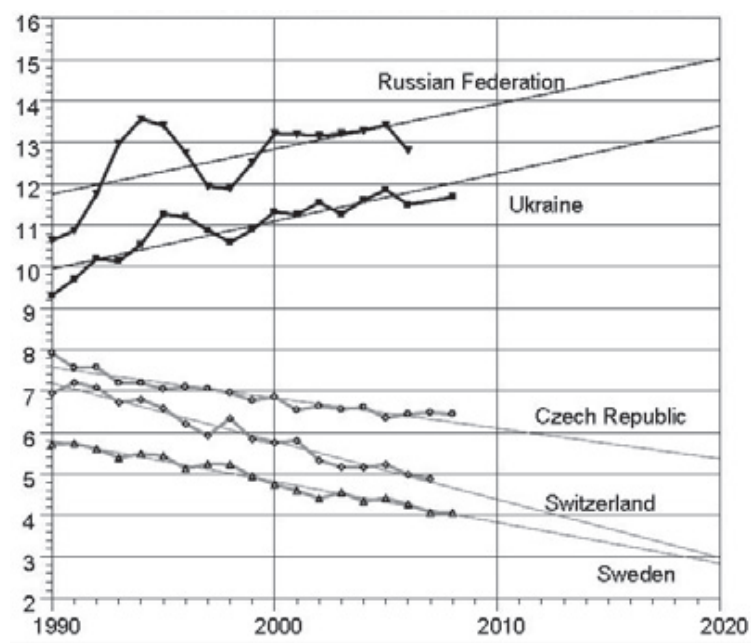

Fig. 5. Different trends of male-female difference of $L E$ in various parts of Europe. According to WHO (2).

\section{Trends of female and male life expectancy in Iceland}

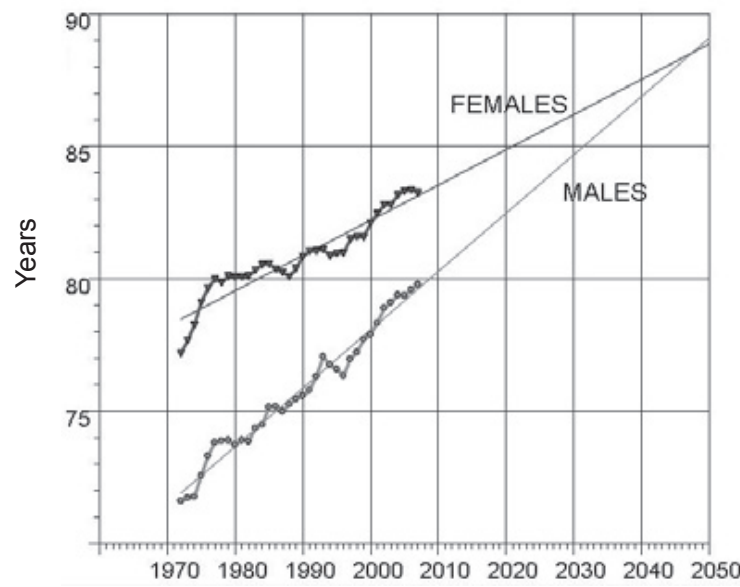

Fig. 6. Hypothetic linear extrapolation of male and female LE in Iceland (according to WHO (2).

As for the prediction of future trends, much depends on the economic and political stability. Extrapolation of present trends for the future in Sweden and Iceland (Figs 4 and 6) suggests possible anullment of the gender gap in LE by the year 2050. Even if this trend will not be of a linear nature, women in 2050 will retain only a modest two year advantage over men.

\section{Endocrinology}

Original explanation for gender differences in the LE and in CVD mortality was based on different metabolic hormonal functions. The incidence of CVD is low in premenopausal women, rises in postmenopausal women, and is reduced to premenopausal levels in postmenopausal women who receive estrogen therapy. Until recently the atheroprotective effects of estrogen were attributed principally to its effect on serum lipids. However, estrogeninduced changes in serum lipids account for only approximately one-third of the observed clinical benefits of estrogen. Current data suggest that the direct actions of estrogen on blood vessels contribute substantially to the cardiovascular protective effects of estrogen. Estrogen increases vasodilation, inhibits the response of blood vessels to injury, and reduces the development of atherosclerosis. Estrogen influences the bioavailability of endothelialderived nitric oxide (NO) and, through NO-mediated increases in cyclic guanosine monophosphate (cGMP), causes the relaxation of vascular smooth-muscle cells (4).

More recently, the traditional explanation that women outlive men solely due to hormonal differences, was subjected to serious criticism. Estrogen levels in postmenopausal women are virtually identical to estrogen levels in males and can hardly explain the discrepancy.

Large population studies using estrogen hormone replacement therapy (HRT) in post-menopoausal women yielded contradictory results regarding CVD protection. Diabetic women who are even at higher risk of atherosclerosis than non-diabetics, responded to HRT with a decline of remnant lipoprotein levels and with an increase in the ,beneficial“ HDL-cholesterol. Although this was considered favorable, long term effect on progression of CVD was not decisive (5).

Past large randomized controlled trials, especially the Women's Health Initiative failed to confirm potential benefit of HRT that was previously suggested by observational studies (6). Possibly harmful outcome, increase in the risk of stroke, venous thromboembolism and breast malignancy resulted in a dramatic worldwide decrease in estrogen HRT (7).

It is uneasy to reconcile these conflicting reports. Pharmacologic dosing of estrogen may differ from effects of the endogenously secreted hormone. The search is on to detect pharmacologically useful, potentially highly selective estrogen receptor modulators.

\section{Molecular biology}

For years it has been acknowledged that genetics demonstrated marked gender differences in chromosomal constitution between males and females. As a result of shrinking Y chromosome the male genomes de facto loose one copy of the $\mathrm{X}$ chromosome information and, as a result, males are characterized by higher mortality (8). An important revelation may come from recent discovery of telomeres (Nobel prize in 2009 for . H. Blackburn, C.W. Greider and J.W. Szostak) (9).

Telomeres are the "caps" at the ends of chromosomes. The DNA molecules that carry genes are packed into chromosomes, and telomeres are found at the ends of the chromosomes. Telomeres, protein-DNA complexes at the ends of eukaryotic chromosomes, are essential for genome stability. The accumulation of chromosomal abnormalities in the absence of proper telomere function is implicated in human aging. Repetitive telomeric sequences are maintained by an enzyme - telomerase. Telomere shortening is associated with DNA damage. Telomere elongation is regulated at multiple levels (10). 
Genetics demonstrate marked gender differences in chromosomal constitution and female preponderance of the life-guard telomeres on chromosomes during mitotic cell division (11). An inverse correlation between mean telomere length and mortality in people has been found. It was confirmed that males have shorter telomeres than females at the same age (12). The longer telomere length in women suggests that for a given chronological age, biological aging of men is more advanced than that of women (13). Telomere shortening in human beings contributes to mortality in many age-related diseases (14). Vascular endothelial cells with senescence-associated phenotypes are present in human atherosclerotic lesions and telomere shortening may contribute to atherogenesis (15) promoting higher risk of CVD mortality in men. High variability of human telomeres is to a large extent genetically determined (16).

Different quality of female telomeres makes genetic causes an important factor contributing to their better LE.

\section{Environmental and other factors}

Temporal changes in the gender LE suggest the role of non genetic factors. Indeed, despite persuasive genetic arguments the opinion persists that the environmental and behavioral factors seem to be more important than the biological ones (17). Alcohol and cigarette consumption, as well as the higher exposure to cancerogenic substances related to typically male professions, are held responsible for this.. Also, risk taking behavior seems to be found more often among males, than among females.

People with a serious mental illness die earlier than the rest of the population. Stress also decreases life expectancy. Overall rates of mental illness are similar for men and women. Many recent studies have concluded that IQ performances of men and women vary only little (18).

Men are more likely to suffer from alcoholism and antisocial personality disorder. Alcohol abuse in men plays a decisive role in the gender gap in LE. Although regional statistics on alcohol consumption have been traditionally inaccurate, health reports on population of the former Soviet Union suggest a prominent negative association between alcohol intake and LE (19-21).

Population in the Russian Federation, men even more than women, has a median LE comparable or even lower than in the developing countries. High CVD mortality in Russia is also related to alcoholism (22). Russian tradition of periodic excessive alcohol intake (binge drinking of 250-500 $\mathrm{ml}$ of vodka) quickly elevates alcohol level to toxic values. Russian women drink less and their LE is impressive 13 years longer than in Russian males (Fig. 1).

Alcohol consumption may be the substantial reason for the phenomenal gender gap in LE of populations belonging to the former Soviet Union (Russian Federation, Ukraine, Belarus, Lithuania, Latvia, Estonia and Moldova).

\section{Conclusion}

Why in some countries men live much shorter than women, while in countries with established socio-economic order this gen- der gap is substantially declining? Cardiovascular morbidity and mortality affects men more than women, decisively contributing to different gender LE. CVD mortality has been dropping in most of the developed world quite dramatically and so has the gender gap also declined.

For many years estrogen activity in women has been considered protective. Estrogen promotes less atherogenic lipid milieu and it is also protective regarding cell metabolism. Endogenously secreted estrogen may function differently from pharmacologic hormone replacement therapy in the postmenopausal women. Initial enthusiasm for a wide use of hormone replacement therapy has been tempered by reports of harmful effects of estrogen. More recently, novel genetic research pointed out marked gender chromosomal differences. Telomeres, protein-DNA complexes at the end of chromosomes, are essential for genome stability. The accumulation of chromosomal abnormalities in the absence of proper telomere function is implicated in human aging. Males have shorter telomeres than females. Most recently the existence of synergism has been proposed between estrogen and telomeres. Estrogen may regulate cell proliferation by a mechanism of reprogramming the size of telomeres in the estrogen target cells. This is achieved by up-regulating the telomerase reverse transcriptase gene in a temporal and spatial manner (23).

Hormonal and genetic sex differences alone cannot explain the relatively rapid change of the gender gap in recent decades. Undoubtedly, environmental factors also have a decisive role. Men abuse alcohol, cigarettes, they are more exposed to environmental hazards, trauma and homicide. These environmental factors may contribute to the excessive gender gap in LE in Russia and in the post communist Europe.

\section{References}

1. World Health Organization. Annex Table 2: Deaths by cause, sex and mortality stratum in WHO regions, estimates for 2002. The world health report 2004 - changing history.

2. European Health for All database (HFA-DB). Copenhagen, WHO Regional Office for Europe, [2010] (http://www.euro.who.int/hfadb).

\section{CIA World Factbook 2009}

4. Viña $\mathbf{J}$, Borrás $\mathbf{C}$, Gambini $\mathbf{J}$ et al. Why females live longer than males: control of longevity by sex hormones. Sci Aging Knowledge Environ 2005; 2005 (23): pe17.

5. Lamon-Fava S, Herrington DM, Horvath KV et al. Effect of hormone replacement therapy on plasma lipoprotein levels and coronary atherosclerosis progression in postmenopausal women according to type 2 diabetes mellitus status. Metabolism 2010; 59: 1794-8000.

6. Danti L. The hormone replacement therapy (HRT) of menopause: focus on cardiovascular implications. Acta Biomed 2010; 81: Suppl 1: $73-76$.

7. Stevenson JC, Hodis HN, Pickar JH et al. Coronary heart disease and menopause management: the swinging pendulum of HRT. Atherosclerosis 2009; 207: 336-340.

8. P. Biecek, S. Cebrat. Why Y chromosome is shorter and women live longer? Eur Phys J B 2008; 65: 149-153. 
9. Gilson E, Ségal-Bendirdjian E. The telomere story or the triumph of an open-minded research. Biochimie 2010; 92 (4): 321-326.

10. Osterhage JL, Friedman KL. Chromosome end maintenance by telomerase. J Biol Chem 2009; 284 (24): 16061-16065.

11. Stindl R. Tying it all together: telomeres, sexual size dimorphism and the gender gap in life expectancy. Med Hypotheses 2004; 62 (1): 151-154.

12. Jeanclos E, Schork NJ, Kyvik KO et al. Telomere length inversely correlates with pulse pressure and is highly familial. Hypertension 2000; 36 (2): 195-200.

13. Benetos A, Okuda K, Lajemi M et al. Telomere length as an indicator of biological aging: the gender effect and relation with pulse pressure and pulse wave velocity. Hypertension 2001; 37 (2 Part 2): 381-385.

14. Cawthon RM, Smith KR, O'Brien $\mathbf{E}$ et al. Association between telomere length in blood and mortality in people aged 60 years or older. Lancet 2003; 361: 393-395.

15. Minamino T, Miyauchi H, Yoshida T et al. Endothelial cell senescence in human atherosclerosis: role of telomere in endothelial dysfunction. Circulation 2002; 105 (13): 1541-1544.

16. Slagboom PE, Droog S, Boomsma DI. Genetic determination of telomere size in humans: a twin study of 3 age groups. Am J Hum Genet 1994; 55: 876-882.
17. Lang E, Arnold K, Kupfer P. Women live longer - biological, medical and sociologic causes. Z Gerontol 1994; 27 (1): 10-15.

18. Deary IJ, Thorpe G, Wilson V et al. Population sex differences in IQ at age 11: the Scottish mental survey 1932. Intelligence 2003; 31: 533-542.

19. Leon DA, Chenet L, Shkolnikov VM et al. Huge variation in Russian mortality rates 1984-94: artefact, alcohol, or what? Lancet 1997; 350: 383-388.

20. Bobak M, McKee M, Rose R, Marmot M. Alcohol consumption in a national sample of the Russian population. Addiction. 1999; 94 (6): 857-866.

21. McKee M. Alcohol in Russia. Alcohol Alcohol 1999; 34 (6): 824-829.

22. Britton A, McKee M. The relation between alcohol and cardiovascular disease in Eastern Europe: explaining the paradox. J Epidemiol Community Health 2000; 54 (5): 328-332.

23. Li H, Simpson ER, Liu JP. Oestrogen, telomerase, ovarian ageing and cancer. Clin Exp Pharmacol Physiol 2010; 37 (1):78-82.

Received January 2, 2011. Accepted August 18, 2012. 